\title{
Drivers of Customer Centricity: Role of Environmental-level, Organization-level and Department-level Variables
}

\author{
Goran Vlašić* \\ Emanuel Tutek
}

\begin{abstract}
Customer centricity is gaining importance as companies are gaining access to increasing amount and quality of individual-level data on identifiable customers. However, efforts to enhance customer centricity often face challenges as they imply organization-wide effort. This paper explores the role of environment-level factors, organization-level factors (in terms of structure, influence and culture) and department-level factors (in terms of integration, power and capabilities) in driving customer centricity of a firm. Results indicate that, while within-category competition stimulates customer centricity, the cross-category competitive intensity limits it. Moreover, marketing competences exhibit highly significant impact which even diminishes the role of inter-departmental integration. Lastly, results show that firms with high level of marketing capabilities and the right culture (in terms of tolerance for failure and availability of slack resources) are likely to exhibit higher levels of customer centricity.
\end{abstract}

Keywords: customer centricity; marketing capabilities; department integration

JEL Classification: M, M3, M31

\section{Introduction}

Since Levitt (1962) stressed the challenges of marketing myopia, which is characterized by firms being focused on pushing their products to customers rather than understanding customers and fulfilling their needs, marketing literature aims to explain the role of customer in business success. Recently, with the development of digital technologies, concept of customer centricity has been regaining importance as customer-centric approach is expected to bring $30 \%$ or higher ROI than marketing ap-

\footnotetext{
* Goran Vlašić is at the Faculty of Economics and Business Zagreb, University of Zagreb, Zagreb, Croatia.
} 
proach which is not customer centric (Marcus and Collins, 2003). In spite of a great promise of customer-centricity, organizations are generally found to only proclaim, rather than truly implement, customer centricity (Shah et. al, 2006).

Customer centricity can be defined as the extent to which an organization is focused on understanding customers and delivering customer-focused solutions (Frankenberger, Weiblen and Gassmann, 2013), and is increasingly becoming integrated part of companies' business models (e.g. Teece, 2010, Amit and Zott, 2001). It "reflects management's hypothesis about what customers want, how they want it, and how the enterprise can organize to best meet those needs, get paid for doing so, and make a profit" (Teece, 2010, p. 172).

Customer centricity implies company's commitment to customer satisfaction (Oliver, 1999) and customer loyalty (Kumar and Shah, 2004). It implies company's interest in truly understanding customers' expectations and its ability to fulfill and exceed the identified expectations. Moreover, it implies company's ability to continuously understand and exceed them, not only at a level of one single transactional relationship. Therefore, companies are increasingly interested in understanding each customer over time and in maximizing the customer lifetime value (Rust, Moorman and Bhalla, 2010; Vankatesan and Kumar, 2004) as an important performance metric.

Customer centric approach generally implies (see Rust, Moorman and Bhalla, 2010): (a) a shift from focusing on product profitability to focusing on customer profitability, (b) change from sales as a performance metric toward using customer lifetime value as performance metric, (c) changing from measuring success by brand equity toward using customer equity for measuring performance, and (d) shifting from market share toward customer equity share as relative performance measure. These changes imply fundamental shifts toward deep understanding of customers and their underlying cognitive, affective, and behavioral processes in order to develop and execute customer-centric strategies.

Understanding customer centricity has been gaining awareness after Kohli and Jaworski (1990) identified the concept of market orientation and Narver and Slater (1990) provided insights into value of market-driven organizations (see Day, 1999). While customer centricity is often proclaimed by companies, research explaining its drivers and how they play out at different levels of analysis is scarce (see Gebhardt, Carpenter and Sherry, 2006). Therefore, in this article, we discuss key drivers of customer centricity analyzing the impact of environment-level factors, organization-level factors (in terms of structure, influence and culture) and department-level factors (in terms of integration, power and capabilities) in driving customer centricity of a firm. 


\section{Hypotheses Development}

Competitive intensity is defined as the extent to which a firm faces competition in a market (Grewal and Tansuhaj 2001; Jaworski and Kohli 1993). It is an important contextual variable (see Kohli and Jaworski, 1990) as it creates threat to organizations and competition over resources and customers (Wieseke et al, 2012) and influences firms' strategic usage of knowledge (Cui, Griffith and Cavusgil, 2005). While competitive intensity has often been discussed as only within-category competition, which increases customers' ability to choose within a certain category (Kumar et al, 2011), in this paper we also focus on cross-category competitive, which implies the extent to which a firm faces competition from other industries in addressing certain customer problem.

Exploring the role of within-category competition, we hypothesize that companies facing low (or no) competition can focus on their product and disregard the market. However, companies that face greater competition are forced to increasingly consider customers and adjust to their preferences. Thus, in context of high within-category competitive intensity, each competitor propels the other toward increased customer centricity. Therefore, we hypothesize:

H1a: The greater the within-category competition a company is facing, the greater the customer centricity of that company.

In case of heightened cross-category competitive intensity, customer is faced with a set of alternative solutions to his/her problem. In such contexts, focusing on firm's customers can blind the company from seeing alternative solutions to customer problems, thus creation customer myopia (see Christensen and Bower, 1996). In such contexts, we argue that firms are likely to focus les on customers and their preferences, and focus more on identifying opportunities which cannot yet be conceptualized by customers. Therefore, we hypothesize:

H1b: The greater the cross-category competition a company is facing, the lower the customer centricity of that company.

Research has shown inconclusive evidence about the role of marketing department in a firm. While some show decreasing importance of marketing department (e.g. Verhoef and Leeflang, 2009; Homburg et al, 2015), others have shown increasing importance of marketing department in a firm (e.g. Merlo, Lukas, and Whitwell, 2012), while some showing positive (e.g. Moorman and Rust, 1999; Feng, Morgan and Rego, 2015), some showing negative (e.g. Götz, Hoelter, and Krafft, 2013) and some showing no impact (e.g. Merlo and Auh, 2009) of marketing department's influence in a firm on the firm's performance. However, regardless of such diverse findings, literature has shown the importance of marketing department's power and capabilities for overall firm-level marketing capabilities (Feng, Morgan and Rego, 2015).

Therefore, as marketing department can be seen as the key carrier of customer centricity, we consider the three key aspects of marketing department. First, we con- 
sider marketing department integration, defined as the extent to which marketing department coordinates with other actors (Verhoef and Leeflang, 2009). We primarily focus on integration of marketing department with two actors that play a key role for customer centricity: (a) marketing agency as an external actor, and (b) sales department as an important internal actor of customer centricity which is in constant interaction with customers. We argue that the greater the integration of key internal and external actors in charge of customer centricity, the greater will be exchange of information on customers, leading to better understanding of customers and greater ability of a company to understand and respond to customer expectations. Therefore, we hypothesize:

H2a: The greater the integration between marketing department and marketing agency, the greater the customer centricity of that company.

$\mathrm{H} 2 \mathrm{~b}$ : The greater the integration between marketing department and sales department, the greater the customer centricity of that company.

Moreover, we consider marketing department's influence on the organization, defined as the extent to which marketing department is involved in strategic and operational decisions within the company, and marketing department's accountability, defined as the extent to which marketing department is able to link marketing strategies and actions to financial performance (see Verhoef and Leeflang, 2009). We argue that the greater the marketing departments influence and accountability, the greater its ability to convince the organization about the importance of customers and their insights for company's performance, thus enhancing company-level customer centricity (see Feng, Morgan and Rego, 2015). Thus, we hypothesize:

$\mathrm{H} 2 \mathrm{c}$ : The greater the marketing department's influence on company's decisions, the greater the customer centricity of that company.

$\mathrm{H} 2 \mathrm{~d}$ : The greater the marketing department's accountability, the greater the customer centricity of that company.

Besides marketing department's integration (with sales department and agency) and its power (thorugh influence and accountability), we consider marketing department's capabilities (see Day, 1994; Vorhies and Morgan, 2005) especially focusing on its ability to plan and manage customer relationships (Shah et al, 2006). Therefore, we define marketing department's capabilities as the extent to which marketing department has knowledge, skills and resources to plan and execute marketing strategy. We argue that marketing departments that are endowed with greater capabilities will be able to better understand and integrate customer insights into company's activities. Therefore we hypothesize:

H3: The greater the marketing department's capabilities, the greater the customer centricity of that company.

Lastly, customer centricity requires company to invest extra effort in understanding and exceeding customer expectations. This requires companies to provide resources and support for employees to meaningfully engage in relationships with cus- 
tomers. Therefore, we argue that important drivers of customer centricity are cultural characteristics of a company that pertain to (a) tolerance for failure and (b) slack, thus motivating employees to go out of their expected roles to understand and satisfy customers. Tolerance for failure allows the company to explore the market and deeply challenge company and industry dogmas thus allowing for the ability to experiment and deliver customer centric solutions. In case of low (or no) tolerance for failure, an organization will remain focused on its internal processes and doing "more of the same". This would lead to companies delivering well known "standardized" solutions and disregard thorough immersion in understanding and responding to customer preferences and needs. On the other hand, slack allows the company to devote enough time and resources to explore the market. Without slack resources, company is focused on delivering efficient solutions and lacks time and/or the resources to deeply understand its customers. Therefore, we hypothesize:

H4a: The greater the tolerance for failure the greater the customer centricity of that company.

H4b: The greater the availability of slack resources, the greater the customer centricity of that company.

\section{Data Collection}

The study consists of three stages. In the first stage, we conducted qualitative interviews with 26 marketing managers, CEOs or company owners in different industries and in two different contexts: developing country and a developed country. The goal of these interviews was to arrive at a practitioners' market driving strategy definition and develop possible items for measuring the variable. Interviews were followed with a pretest ( $n=63$ managers in a developed and a developing country). Then we administered a large-scale web-based survey among marketing managers or others in charge of marketing activities (e.g. CEOs or owners in smaller firms). We used the AMADEUS database to get a list of eligible firms in one European country. From that list we contacted 1.573 companies by sending personalized e-mails explaining the purpose of the study and with a link to the web survey.

We had a total of 315 responses (20,03\% response rate), i.e. those that have reached the end of the survey. From this set, we excluded: (1) incomplete responses, (2) responses that ware completed in a significantly shorter time than it took the test respondents (showing that respondents did not devote enough attention to the task), (3) responses that did not provide comparable answers to control questions (implying that respondents did not have adequate concentration throughout the task), (4) responses by individuals who are not marketing managers (or other function in charge of marketing), and (4) responses by incompetent respondents (Homburg and Jensen, 
2007). As a result we arrived to the 255 usable questionnaires which is a response rate of $16,21 \%$, which is comparable to other research targeting marketing managers as respondents (e.g. Verhoef and Leeflang, 2009)

Where possible, to measure constructs we used existing measures from the literature refining them to fit the purpose. We assessed the validity and reliability of scales, checked for common method bias, directional bias, respondents' focus, and multicollinearity.

Table 1: Customer Centricity

\begin{tabular}{|c|c|c|c|c|c|}
\hline \multirow[t]{2}{*}{ DV: } & \multicolumn{5}{|c|}{ Customer Centricity } \\
\hline & (1) & (2) & (3) & (4) & $(5)$ \\
\hline Within-category competition & $\begin{array}{l}.142 * * \\
(.068)\end{array}$ & $\begin{array}{l}.142 * * \\
(.066)\end{array}$ & $\begin{array}{l}.148 * * \\
(.066)\end{array}$ & $\begin{array}{l}.184 * * * \\
(.064)\end{array}$ & $\begin{array}{l}.182 * * * \\
(.062)\end{array}$ \\
\hline Cross-category competition & $\begin{aligned}-.133^{*} \\
(.068) \\
\end{aligned}$ & $\begin{array}{c}-.148 * * \\
(.068) \\
\end{array}$ & $\begin{array}{c}-.155^{* *} \\
(.067) \\
\end{array}$ & $\begin{array}{c}-.139 * * \\
(.064) \\
\end{array}$ & $\begin{array}{r}-.121 * \\
(.063) \\
\end{array}$ \\
\hline $\begin{array}{l}\text { Marketing department's integration with } \\
\text { Marketing agency }\end{array}$ & & $\begin{array}{c}.095 \\
(.069) \\
\end{array}$ & $\begin{array}{c}.089 \\
(.070)\end{array}$ & $\begin{array}{c}.083 \\
(.067)\end{array}$ & $\begin{array}{c}.050 \\
(.067)\end{array}$ \\
\hline $\begin{array}{l}\text { Marketing department's integration with Sales } \\
\text { department }\end{array}$ & & $\begin{array}{l}.153 * * \\
(.066) \\
\end{array}$ & $\begin{array}{l}.136^{* *} \\
(.066) \\
\end{array}$ & $\begin{array}{c}.061 \\
(.066)\end{array}$ & $\begin{array}{c}.039 \\
(.067)\end{array}$ \\
\hline Marketing department's Influence & & $\begin{array}{c}.142 \\
(.096)\end{array}$ & $\begin{array}{c}.123 \\
(.096)\end{array}$ & $\begin{array}{c}.080 \\
(.092) \\
\end{array}$ & $\begin{array}{c}.095 \\
(.090)\end{array}$ \\
\hline Marketing department's Accountability & & $\begin{array}{c}.026 \\
(.099) \\
\end{array}$ & $\begin{array}{c}.025 \\
(.098) \\
\end{array}$ & $\begin{array}{l}-.083 \\
(.097) \\
\end{array}$ & $\begin{array}{l}.073 \\
(.096) \\
\end{array}$ \\
\hline CEO Experience Breadth & & & $\begin{array}{c}.049 \\
(.068) \\
\end{array}$ & $\begin{array}{l}-.010 \\
(.066)\end{array}$ & $\begin{array}{c}-.037 \\
(.066) \\
\end{array}$ \\
\hline CEO Experience Depth & & & $\begin{array}{l}.126^{*} \\
(.068)\end{array}$ & $\begin{array}{l}.117 * \\
(.066)\end{array}$ & $\begin{array}{c}.089 \\
(.065)\end{array}$ \\
\hline Marketing department's Capability & & & & $\begin{array}{c}.330 * * * \\
(.074)\end{array}$ & $\begin{array}{c}.235 * * * \\
(.078)\end{array}$ \\
\hline Tolerance for Failure & & & & & $\begin{array}{l}.135 * * \\
(.069) \\
\end{array}$ \\
\hline Slack resources & & & & & $\begin{array}{c}.156^{* *} \\
(.069)\end{array}$ \\
\hline Constant & $\begin{array}{l}-.025 \\
(.063)\end{array}$ & $\begin{array}{l}-.047 \\
(.062)\end{array}$ & $\begin{array}{l}-.058 \\
(.061)\end{array}$ & $\begin{array}{l}-.070 \\
(.059)\end{array}$ & $\begin{array}{l}-.081 \\
(.058)\end{array}$ \\
\hline $\mathrm{F}$ & $2.907 *$ & $4.100 * * *$ & $3.772 * * *$ & $5.841 * * *$ & $6.036 * * *$ \\
\hline $\mathrm{R}^{2}$ (overall) & .026 & .102 & .124 & .198 & .239 \\
\hline Sig $R^{2}$ change & $.026^{*}$ & $.077 * * *$ & $.021 *$ & $.074 * * *$ & $.041 * * *$ \\
\hline
\end{tabular}

Significance levels: $*<0.1 ; * *<0.05 ; * * *<0.01$

\section{Results and Discussion}

The firms in our sample operate equally on B2B and B2C markets with mean 3.97 on a 7-point scale ( 1 = "turnover totally from B2B", and 7 = "turnover totally from 
B2C"). They are somewhat more product-focused with mean 3.68 on a 7-point scale ( 1 = "turnover totally from goods", and $7=$ "turnover totally from services"). Most of the firms in our sample are "small", i.e. up to 50 employees (49.4\%), 19.2\% are medium sized (from 51 to 250 employees), $15.3 \%$ are large (251 to 1000 employees) and $16.1 \%$ are very large (above 1000 employees). In our models we controlled for CEO characteristics' influence on customer centricity (for discussion see Herhausen, De Luca and Weibel, 2017).

Results show that within-category competition propels organizations toward customer centricity $(\beta=, 142 ; p=, 037)$ while cross-category competition deters them from being customer centric $(\beta=-, 133 ; p=, 052)$ thus confirmed H1a and H1b. These results are interesting as they show that competitive intensity should not be considered as a simple variable but a multifaceted construct whose elements can have differing effects on firm's activities. In this case, while one type of competitive intensity (within-category) requires companies to deeply understand and cater to consumers' preferences, the other type of competitive intensity (cross-category) stimulates companies to detach themselves from customers and their demands in order to be able to "look beyond" what customers are able to envision (Henry Ford reflects this idea in saying "If I had asked people what they wanted, they would have said faster horses" quoted by Vlaskovits, 2011).

Further, results show that organizational factors pertaining to marketing that can stimulate customer centricity relate to marketing department's integration with sales as an internal actor $(\beta=, 153 ; p=, 021)$ while its integration with marketing agency does not have significant impact on customer centricity $(\beta=, 095 ; p=, 171)$ thus leading us to reject $\mathrm{H} 2 \mathrm{a}$ and accept $\mathrm{H} 2 \mathrm{~b}$. As marketing and sales are working together within the same company, the more integrated they are the more closely they will understand the customer with sales having "field data" and marketing having the "market data" allowing them to enhance customer centricity. On the other hand, integration of marketing department with marketing agency tends not to focus on understanding and delivering solutions to customers, but is primarily concerned with developing and delivering messages through advertising, thus having no significant impact on customer centricity of an organization. Interestingly, when marketing department's capability is introduced to the model, its impact on customer centricity is so significant $(\beta=, 330$; $\mathrm{p}=, 000$; confirming H3) that even the marketing department's integration with sales department loses significance in the model (see model 4). This implies that truly capable marketing department is able to understand both the "field data" and the "market data" thus making its integration with sales department less important for company's customer centricity.

Lastly, variables focusing on culture show that both tolerance for failure $(\beta=, 135$; $\mathrm{p}=, 050)$ and slack resources $(\beta=, 156 ; \mathrm{p}=, 025)$ have significant and positive impact on customer centricity of a company, thus confirming H4a and H4b. This implies that company needs to allow time and resources for exploration of customer's needs (even 
latent needs) which inherently is characterized by higher risk (as compared to a situation where company focuses on enhancing its current activities).

\section{Concluding Remarks}

Customer centricity is gaining importance in the contemporary context of globalized interactions facilitated by technological advancements (see Gaurav and Shainesh, 2016). This research contributes by identifying the conditions that stimulate companies' costumer centricity, differentiating factors that company has to adjust to and those it can impact.

In that sense, companies facing high within-category competitive intensity generally exhibit greater customer centricity than companies in low within-category competitive context. Within-category competition provides customers with choice thus forcing companies to develop deep understanding of customers and outperform competitors on how well they respond to customer expectations. On the other hand, companies that face high cross-category competition are likely to be less customer centric since their customers are shifting across industries to satisfy their needs. In such contexts if companies are customer centric, they run a risk of facing customer myopia due to customers' inability to visualize future developments (see Christensen and Bower, 1995).

Focusing on department-level variables, results indicate that marketing department's integration with sales department will lead to greater customer centricity of the company, as information about the customers will be more easily collected, circulated and acted upon within the company. However if marketing department is characterized by high level of capability in managing customer relationships, the importance of integration with sales department diminishes. Interestingly, integration with marketing agency (as an external actor) has no impact on firm's customer centricity. This implies that customer centricity cannot be outsourced but should be nurtured within a company, supported by a highly capable marketing department.

Our results indicate that nurturing customer centricity within a company implies a culture which is characterized by slack, allowing employees extra time and resources to deliver outstanding experiences to customers, while at the same time exhibiting tolerance for failure, thus allowing employees to experiment in identifying opportunities to amaze the customer.

Thus, our results indicate that structural factors are of lower importance for customer centricity as compared to having a highly capable marketing department operating under adequate corporate culture which exhibits tolerance for failure and allows for slack. Our results also indicate that possible deficiencies in marketing department's capabilities can be mitigated by integrating marketing and sales depart- 
ments of the company thus complementing marketing's focus on markets with "field data" on customers.

Further research should focus on exploring the impact of customer centricity on firm performance under diverse market/firm/offering conditions. Moreover, further research should explore possible industry-specific challenges in delivering on customer centricity. Lastly, further research should explore short-term vs. long-term influence of customer centricity on delivering value to the firm vs. value to the customers.

\section{REFERENCES}

Amit, R., and Zott, C. (2001): „Value creation in E-business“, Strategic Management Journal, 22 (6-7): 493-520.

Christensen Clayton M., Bower Joseph L. (1996): „Customer power, strategic investment, and the failure of leading firms“, Strategic Management Journal, 17 (3): 197-218.

Cui, Anna Shaojie, David A. Griffith, and S. Tamer Cavusgil (2005), „The Influence of Competitive Intensity and Market Dynamism on Knowledge Management Capabilities of Multinational Corporation Subsidiaries“, Journal of International Marketing, 13 (3), 32-53

Day, George S. (1994), “The Capabilities of Market-Driven Organizations”, Journal of Marketing, 58 (October), 37-52.

Day, George S. (1999): „The Market-Driven Organization“, New York: Free Press

Frankenberger Karolin, Weiblen Tobias, Gassmann Oliver (2013): „Network configuration, customer centricity, and performance of open business models: A solution provider perspective“, Industrial Marketing Management, 45 (5): 671-682

Gaurav Rajesh and Shainesh G. (2016): „The Changing Face of Customer Centricity“ in The Palgrave Handbook of Managing Continuous Business Tranformation (ed. Ellermann Horst, Kreutter Peter, and Messner Wolfgang: Palgrave, p. 175-187.

Gebhardt, Gery; Carpenter, Grogory; and Sherry, John (2006): "Creating Market Orientation: A Longitudinal, Multi-firm, Grounded Analysis of Cultural Transformation,” Journal of Marketing, 66 (4), 37-55.

Götz, Oliver, Ann-Kristin Hoelter, and Manfred Krafft (2013), “The Role of Sales and Marketing in Market-Oriented Companies“, Journal of Personal Selling and Sales Management, 33 (4), $353-71$.

Grewal, Rajdeep and Patriya Tansuhaj (2001), "Building Organizational Capabilities for Managing Economic Crisis: The Role of Market Orientation and Strategic Flexibility", Journal of Marketing, 65 (April), 67-80.

Herhausen Dennis, De Luca Luigi, and Weibel Michael (2017): „The interplay between employee and firm customer orientation: Substitution effect and the contingency role of performance-related rewards", British Journal of Management, forthcoming.

Herhausen, Dennis; De Luca, Luigi; Miceli, Gaetano "Nino"; Morgan, Robert E. and Schögel, Marcus (2017): „When Does Customer-Oriented Leadership Pay Off? An Investigation of Frontstage and Backstage Service Teams“, Journal of Service Research, forthcoming.

Homburg, Christian, Arnd Vomberg, Margit Enke, and Philipp H. Grimm (2015), "The Loss of the Marketing Department's Influence: Is It Really Happening? and Why Worry?”, Journal of the Academy of Marketing Science, 43 (1), 1-13. 
Hui Feng, Neil A. Morgan, and Lopo L. Rego (2015), „Marketing Department Power and Firm Performance“, Journal of Marketing, 79 (September), 1-20

Jaworski, Bernard J. and Ajay K. Kohli (1993), "Market Orientation: Antecedents and Consequences", Journal of Marketing, 57 (July), 53-70

Kohli, Ajay K. and Bernard J. Jaworski (1990): "Market Orientation: The Construct, Research Propositions," Journal of Marketing, 54 (2): 1-18

Kumar V., Eli Jones, Rajkumar Venkatesan, and Robert P. Leone (2011), „Is Market Orientation a Source of Sustainable Competitive Advantage or Simply the Cost of Competing?", Journal of Marketing, 75 (January), $16-30$

Kumar, V. and Denish Shah (2004): "Building and Sustaining Profitable Customer Loyalty for the 21st Century," Journal of Retailing, 80 (4): 317-329.

Levitt, T. (1962): „Innovation in marketing: New perspectives for profit and growth“, New York: McGraw-Hill.

Marcus, Claudio and Kimberly Collins (2003): "Top-10 Marketing Processes for the 21st Century," Gartner Group Report SP-20-0671. http://www.gartner.com

Merlo, Omar and Seigyoung Auh (2009), "The Effects of Entrepreneurial Orientation, Market Orientation, and Marketing Subunit Influence on Firm Performance”, Marketing Letters, 20 (3), 295-311.

Merlo, Omar, Bryan A. Lukas, and Gregory J. Whitwell (2012), "Marketing's Reputation and Influence in the Firm", Journal of Business Research, 65 (3), 446-52.

Moorman, Christine and Roland T. Rust (1999), "The Role of Marketing”, Journal of Marketing, 63 (Special Issue), 180-97.

Narver, John C. and Stanley F. Slater (1990): "The Effect of a Market Orientation on Business Profitability," Journal of Marketing, 54 (4): 20-35

Oliver, Richard L. (1999): "Whence Consumer Loyalty?" Journal of Marketing, 63, 33-44.

Rust Roland T., Moorman Christina, and Bhalla Gaurav (2010): „Rethinking Marketing“, Harvard Business Review, January-February, 1-8.

Shah Denish, Rust T. Roland, Parasuraman A., Staelin R. and Day, George S. (2006): „The Path to Customer Centricity“, Journal of Service Ressearch, 9 (2): 113-124

Shah, Denish, Roland T. Rust, A. Parasuraman, Richard Staelin, and George S. Day (2006), "Path to Customer Centricity", Journal of Service Research, 9 (2), 113-24.

Teece, D. J. (2010): „Business Models, Business Strategy and Innovation“, Long Range Planning, 43 (2-3): 172-194.

Venkatesan, Rajkumar and V. Kumar (2004): "A Customer Lifetime Value Framework for Customer Selection and Resource Allocation Strategy," Journal of Marketing, 68 (4): 106-125.

Vlaskovits Patrick (2011): "Henry Ford, innovation, and Thet 'Faster Horse' Quote“, Harvard Business Review, August.

Vorhies, Douglas W. and Neil A. Morgan (2005), "Benchmarking Marketing Capabilities for Sustainable Competitive Advantage", Journal of Marketing, 69 (January), 80-94.

Wieseke, Jan, Florian Kraus, Michael Ahearne, and Sven Mikolon (2012), „Multiple Identification Foci and Their Countervailing Effects on Salespeople's Negative Headquarters Stereotypes“, Journal of Marketing, 2012, 1-20 Vol 76 (May) 